\title{
Energy Analysis of a Small Geothermal District Heating System in Southern Italy
}

\author{
Alberto Carotenuto ${ }^{1}$, Giuseppina De Luca ${ }^{1}$, Salvatore Fabozzi ${ }^{1 *}$, Rafal Damian Figaj ${ }^{1}$, Marina \\ Iorio $^{2}$, Nicola Massarotti ${ }^{1}$ and Laura Vanoli ${ }^{1}$ \\ ${ }^{1}$ Department of Engineering, University of Naples Parthenope Centro Direzionale. IS.C4, 80133 \\ Naples, Italy \\ 2 Istituto per l'Ambiente Marino Costiero, Consiglio Nazionale delle Ricerche, Calata Porta di Massa, \\ Porto di Napoli, 80133 Naples, Italy
}

Email: salvatore.fabozzi@unipathenope.it

\begin{abstract}
Small and medium size district heating networks have seen some spread over the last two decades, especially in cities which are not supplied by natural gas grids. In this paper, the authors investigate the energetic feasibility of a small district heating network feeding two schools in a city of Southern Italy (Mondragone). In particular, the district heating is powered by a low-temperature geothermal fluid pumped from a well located $2.1 \mathrm{~km}$ away from the city center. Geothermal fluid has a temperature of $34^{\circ} \mathrm{C}$ and a flow rate of $6 \mathrm{l} / \mathrm{s}$. The buildings have been rehabilitated by an energy point of view and are equipped of low-temperature fan-coils in order to ensure their compatibility with the $4^{\text {th }}$ generation district heating system. Energy analysis were conducted through the implementation of transient simulation model in TRNSYS environment. The feasibility of two configurations of the system is compared: the first, with one heat pump installed nearby the geothermal well feeding the grid, and the second one with the heat pumps installed in each building substation. Transient simulations results show that the first configuration is energetically less efficient than the second one due to the high thermal losses $(55 \%$ of the total consumption) of the district supply pipes.
\end{abstract}

Keywords: District heating, Geothermal energy, Heat pump, Efficiency, Renewable energy.

\section{INTRODUCTION}

Over the last 40 years, an important attention was given within the scientific production to climate change [1]. The measures of European Union known as "20-20-20" targets [2], must be reached all over the Europe. One of the three targets aims to increase the use of renewable energy source of the $20 \%$ respect the 1990 ones [4]. This objective can be achieved even through the use of geothermal energy that could provide a contribution to reduce the fossil fuel consumption and the environmental problems [3], as stated even in the European directive 2009/28/EC [4].

Data collected in 2010 show that the electricity production in Italy from geothermal source was equal to $1.8 \%$ of the total national [5] one. The two geothermal plants located in Tuscany area (Larderello-Travale/Radicondoli and Mount Amiata) produce $5700 \mathrm{GWh}_{\mathrm{e}}$ [6].

Possible uses of geothermal resources can vary as a function of geothermal fluid temperature [7-8].

Electricity energy production for temperatures higher than $90^{\circ} \mathrm{C}$; direct uses of thermal energy for space heating and industrial and agriculture production with temperature lower than $90{ }^{\circ} \mathrm{C}$ and, finally, in the case of fluid temperature between 30 and $50{ }^{\circ} \mathrm{C}$ for special processes [9] .
In particular, in this paper, the authors analyze the energy feasibility of a small district heating network feeding two schools in a city in southern Italy (Mondragone), which benefited the funds for the redevelopment of school buildings.

Sustainable district heating serving the public buildings and the improvement of the materials used for construction [10] can have significant effect on reducing of the GHG emission and the air pollution [11]. A centralized local thermal energy system, which can produce hot and cold fluid, and then distribute them throughout the community, has a significant potential to contribute to solving society's energy challenges [12].

Many papers [13-17] across the district heating in Italy showed that the small and medium networks have had some spread over the last two decades in the northern Italy. The most part of these networks are powered by thermal energy obtain from renewable sources. In the Mediterranean area, there are not district heating networks because the cooling demand is higher than the thermal one such the district networks construction is not economically viable. In the Izmir city, in Balcova area (Turkey), a district heating/cooling has been built [18]. Ozgener et al. [18] focused their work on network losses heat exchangers losses, pumps and fuel 
consumption in order to outline a feasibility study of the system. It therefore appears, there still be a relevant space for the study and the realization of initiatives of this type, as well as for the dissemination of networks that allow to recovery thermal energy produced by the industries or from a geothermal source and transfer it to the users surrounding, for example civil, industrial or agricultural utilities.

\subsection{Geothermal source}

It is important to remark that this work connected to the Vigor project [19], which aims at the developing of methods and technologies suited to promote the use of geothermal energy in Campania region (Southern Italy).

Within this project, a geothermal site has been located near the town of Mondragone.

The city has a population of 27,000 inhabitants and is located in the northern part of the Campania region, in the province of Caserta. The town is built on a small hill about 10 $\mathrm{m}$ above sea level, between the rivers Garigliano and Volturno. The municipal area is about $54 \mathrm{~km}^{2}$. Inside this one, it is situated entirely the area objective of the project, which covers about $20 \mathrm{~km}^{2}$ [20]. The other data of the city are summarized in Table 1 [21].

Table 1. Urban Setting

\begin{tabular}{ll}
\hline City & Mondragone \\
\hline Climatic Area & $\mathrm{C}$ \\
\hline Heating degree days (HDD) & 1.060 \\
\hline Heating Season & 16th November - 31th March \\
\hline
\end{tabular}

In this area are identified two thermal anomalies related to sources of two areas called "Le Vagnole" and "Palude" (Santa Maria dell'Incaldana/Petrinum well). The water source used for the purposes of this study consists of Petrinum well, located in the northern part of the town, as shown in Figure 1. In this figure, the target area subject of study and the site location of interest are identified by the red line and dot, respectively.

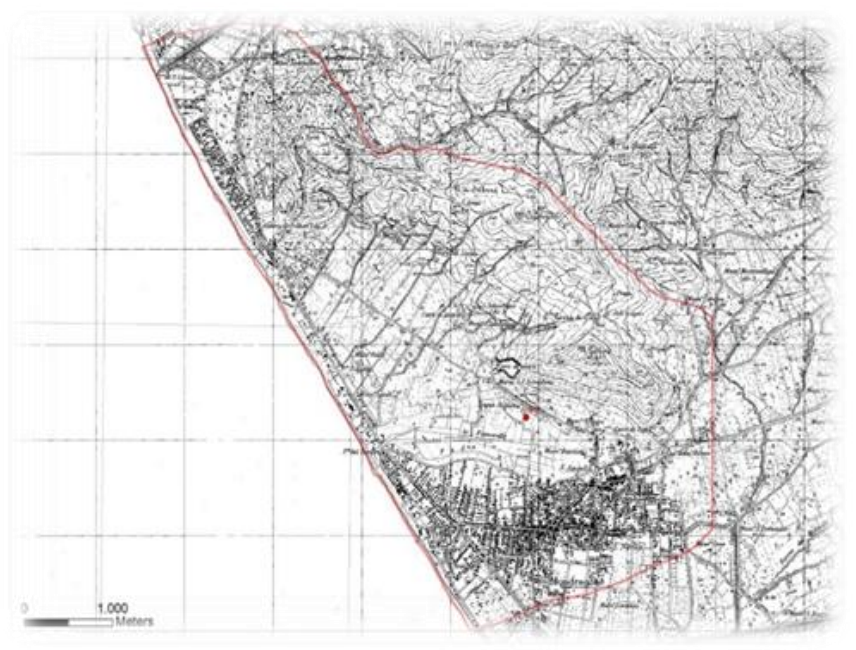

Figure 1. Site location of interest

In Mondragone town evidence of hydrothermal activity are known since the III century BC.
Geothermal system is characterized by surface manifestations of thermal mineral waters with a maximum temperature of about $50^{\circ} \mathrm{C}$ and high gas content [19].

The analysis of past data and the new data acquisition has been performed, and it allowed to specify the presence in the target area of a system of hydrothermal circulation. The data outlined for the Padula/Petrinum well area a temperature not less than $33^{\circ} \mathrm{C}$ and, a maximum flowrate of $23 \mathrm{l} / \mathrm{s}$ that can be suitable for a direct use of geothermal source [22].

According to the measurements conducted on wells surrounding the case study area and on the surveys conducted in the drilling field, it has been possible to reconstruct a continuous log of the geothermal fluid temperatures inside the well (and with a temporary casing). The main change temperatures intervals for the heating plant interest depths are summarized in Table 2

Table 2. Geothermal Water Temperature

\begin{tabular}{|l|l|}
\hline Depth from ground level $(\boldsymbol{m})$ & Temperature $\left({ }^{\circ} \mathbf{C}\right)$ \\
\hline \hline $0-32$ & $38.5-40.00$ \\
\hline $32-124$ & 40.00 \\
\hline $124-160$ & $40.00-36.00$ \\
\hline
\end{tabular}

The available geothermal source can be classified as conventional, because its exploitation is closely linked to the presence of a hydrothermal system at low enthalpy, since the temperatures of the fluid does not reach $50^{\circ} \mathrm{C}$.

Once defined the geothermal reservoir, the possible uses of the resource have been investigated, by analyzing the context of Mondragone city by a social and economic point of view.

\subsection{Case study}

After the examination of various design assumptions, it has been decided to develop a district heating network at service of seven public school buildings.

It is important to note that the development of the network is planned in two different steps:

- first, it will be built the main loop and two branches that connect only two schools buildings using $6 \mathrm{l} / \mathrm{s}$ with respect to to the maximum available flow rate equal to $23 \mathrm{l} / \mathrm{s}$ (Leonardo da Vinci and II Circolo) (scenario 1);

- subsequently the network will be further extended in the area and the energy carrier will reach, through a widespread distribution, seven schools using the maximum available flow

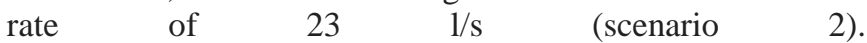
This work presents the results for the scenario 1 where only two schools are connected to the district heating network. In this scenario, two configurations relating to the different positioning of the heat pumps were analyzed (Classic DHC configuration, Substation DHC configuration).

\section{SYSTEM LAYOUT}

The Central Thermal Plant DH Configuration and the Substation DH Configuration are reported in Figure 2 and 3, respectively; where for sake of clarity only the main components are displayed.

The Figure 2 shows the system configuration with the heat pump installed nearby the geothermal well, whereas the second one shows the system configuration when the heat pumps are installed in each building. Both systems are used 
in order to provide space heating in the winter season (from $16^{\text {th }}$ November to $31^{\text {st }}$ March) [23]. The traditional DH system (central thermal plant) provides space heating to the users with a hot fluid (produced by the reversible heat pump) that is distributed with a piping ring among the system users. In particular, the presence of a heat exchanger, installed on the district piping line and couple $\mathrm{d}$ with the hydronic system of each user, ensures the thermal energy supply in order to satisfy the thermal demand of the building. In the substation DH configuration, the district water temperature is increased by a heat exchanger supplied by hot well (aquifer) water. The district piping system fluid is successively supplied (at low temperature) by the piping system to the load side of the reversible heat pumps of each building.

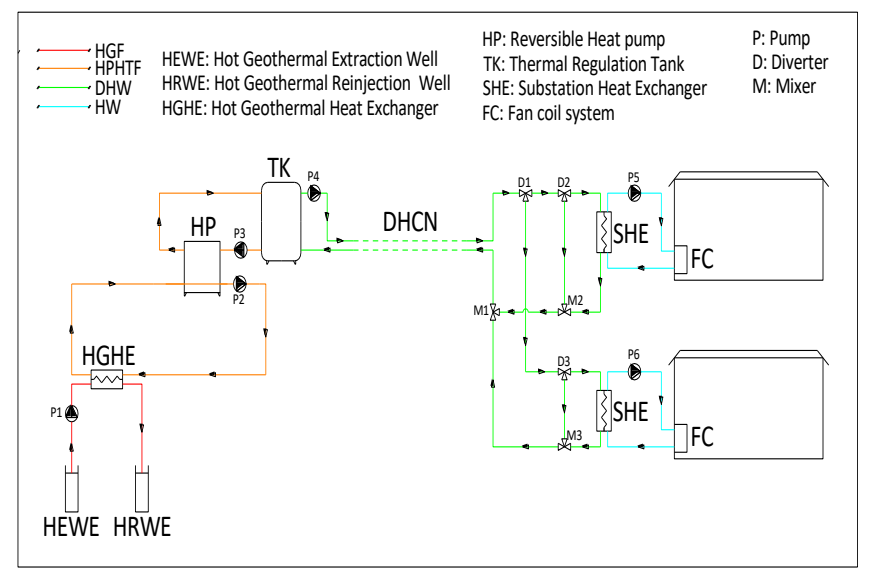

Figure 2. Central thermal plant DH Layout

The system layout includes several operating fluids, namely:

- hot geothermal fluid, HGF: geothermal hot fluid flowing from the submersible pump in the well to the geothermal heat exchanger in the central plant;

- heat pump heat transfer fluid, HPHTF; water flowing from the geothermal heat exchanger to the evaporator of the heat pumps and flowing from the condenser of the reversible heat pumps to the thermal regulation tanks;

- district hot water, DHW: water flowing inside the piping system of the district heating system;

- hot water, HW: circulating hot water in the building hydronic system;

The main components are as follows:

- a geothermal extraction well, HEWE, which provides hot geothermal water to the hot geothermal heat exchanger;

- a geothermal reinjection well, HRWE, which reinjects hot geothermal water to the deep aquifer;

- a geothermal heat exchanger, HGHE, used to supply the source side of heat pump with geothermal energy or to heat the district piping system fluid;

- a water to water heat pump, HP;

- thermal regulation hot water storage tanks, TK, used in order to reduce the number of on/off events of the reversible heat pump HP and in order to ensure a proper operation of the district heating/cooling network and of the hydronic system of the buildings;

- a district heating network, DHN consisting of a buried piping system used in order to transport the thermal energy to the district users;

- two substation heat exchangers, SHE, used in order to transfer the heat between the district hot water DHW to the hydronic system water of each building;
- a fan coil system, FC, that supplies thermal energy for space heating of the building accordingly to the indoor temperature control strategy.

- some fixed-volume pumps, $\mathrm{P}$, for the fluids loops.

- some flow mixers, M, and diverters, D, adopted in order to control and distribute the fluid circulating within the loops.

- some additional components: sensors, controllers (feedback and on/off with hysteresis) and schedulers (daily, weekly and seasonal). These components are not displayed in Figure 2, for brevity.

The presented district heating system (DH) was modelled and dynamically simulated in TRNSYS software [24]. In TRNSYS environment were implemented other mandatory components (weather database, plotters, printers, integrators) in order to perform the system simulation and to obtain the output data. Moreover, the system components were set with accurately selected design parameters in order to perform a correct system operation and to meet the energy demand of the system users, e.g. set-point temperatures, temperature deadbands for the components and system operation time schedule.

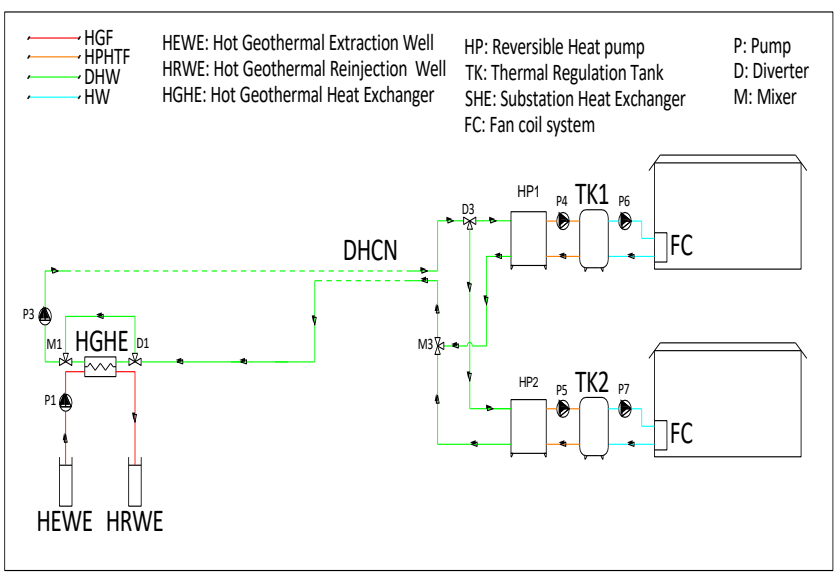

Figure 3. Substation DH Layout

The basic operating principle and the controls strategies of the system are summarized in the following subsections. The two system layouts (classic and substation configuration) are similar thus the operation principle is quite similar for both layouts. The building fan coil system is independent with respect to the district system configuration. In particular, for both configurations the space heating/cooling strategy is described as follows. In winter, when the building indoor zone air temperature falls below $19^{\circ} \mathrm{C}$, the hot fluid of the hydronic system is supplied to the fan-coils. In this case, the air temperature rises up to $21^{\circ} \mathrm{C}$.

\subsection{Central thermal plant DH configuration}

The HGF is extracted by the submerged pump P1 and across M1 is supplied to the hot side of HGHE. This one heats the HPHTF flow that is managed in the closed loop by P3. From the cold outlet side of HEWE the geothermal heated HPHTF is supplied to the evaporator side of the district HP. From the outlet condenser side of HP the heated HPHTF is supplied by P4 to the regulation tank TK1 in order to achieve a $55^{\circ} \mathrm{C}$ set point temperature. The tank feeds the district piping system by P5, then the hot water is transported to D2 where is switched in the substation heat exchangers SHE in order to satisfy the buildings space heating demand. The presence of diverters D3, D4 and mixers M3, M4 
configure a by-pass circuit for the SHEs'. This solution is adopted in order to control the inlet temperature of the hydronic system (outlet cold side of SHE). In particular, an iterative feedback controller regulates the flow of D3 (D4) to SHE in order to achieve the set point temperature of $45^{\circ} \mathrm{C}$.

At the hot outlet side of SHEs the hot district fluid passes via M3/M4 and M2 and returns to the thermal regulation tank TK1. During the district heating functioning hours, the geothermal energy extraction is regulated by the top temperature of TK1. In particular, when this temperature is not within the fixed deadband $\left(50 \div 55{ }^{\circ} \mathrm{C}\right)$ the activation of HP and pumps P1, P2, P3 is mandatory to heat the tank to the set point temperature. This strategy is performed in order to minimize the electric energy consumption of the extraction/circulation pumps and of the heat pump.

During the night the district system is turned off and the temperature inside the piping network decreases due to the thermal losses to the surrounding ground, thus at the beginning of the building hydronic system activation the temperature of the supplied district hot fluid is too low to satisfy the space heating demand. As a consequence, the activation of the district heating network occurs one hour before the start of the space heating inside the buildings, because the district hot fluid produced by HP and supplied by TK1 takes about one hour to reach the substation heat exchangers.

\subsection{Substation DH configuration}

This layout is similar to the classic one; the difference is that the district fluid DHW is heated directly by the geothermal heat exchangers and in each building a heat pump coupled with a regulation tank is installed. In winter, HGF is supplied through to the hot side of HGHE by means of P1, so the district hot fluid circulating on the cold side of HGHE is heated. This fluid is pumped by P3 across the district piping system to D3 in order to supply the substations reversible heat pump evaporator. Similarly to the central thermal plant configuration, from the condenser side of HP1 (HP2) the HPTF is supplied by P4 (P5) to the hydronic system thermal regulation tank TK1 (TK2) until is reached the desired set point temperature $\left(55^{\circ} \mathrm{C}\right)$. From the top side of TK1 (TK2) the heated water is supplied to the building fan coil system in order to satisfy the buildings space heating demand.

Furthermore, the hydronic heating system operates without HP contribution when the top temperature of the regulation tanks is within the fixed dead bands temperatures, $50-55^{\circ} \mathrm{C}$.

The described operation is possible due to TK1 (TK2) thermal energy storage capacity. This control strategy is performed in order to avoid the unnecessary power consumption of the heat pumps and the related circulation pumps when the thermal regulation tanks are thermally loaded. As for the classic configuration, the district system is activated one hour before the space heating/cooling activation inside the buildings due to the district fluid transport time.

\section{MODEL}

The system described in the previous section was modelled and dynamically simulated in TRNSYS [24]. This software includes a large library of built-in components, often validated by experimental data [25], and allows one to calculate energy, mass flows and temperature profiles for the components of the system for whatever time period. Moreover, with the tool is possible permits to evaluate the energetic performance of the system under investigation due to the capability to integrate the data on whatever time period (hours, days, weeks, months or years). In order to perform the system modeling, some components models were taken from the software library (e.g. pumps, mixers, diverters, valves, controllers, gas burner, reversible water to water heat pump, building, etc.), while specific models have been also developed for the calculations of primary energy savings and for the management/control of the system. It is worth noting that, all models of the components included in the software library and implemented in the system are validated against experimental and/or manufacturer data. For example, the reversible heat pump model is based on manufacturer's data, so its performance is intrinsically validated. A complete validation of the system as a whole is not possible because the system is not realized, but all models of the components included in the systems are very reliable and validated.

For sake of brevity, in the following only a brief description is reported only for the main system components (building, reversible heat pump and pipes); a detailed description of the all models used for the remaining components is available in the TRNSYS reference [25] type $3 \mathrm{~b}$ for the single velocity pumps, type 751 for GB, type 60 for TK1, Type 11 for diverter and mixers, type 91 for the geothermal heat exchanger.

\subsection{Building}

The buildings are modeled in TRNSYS with TRNBUILD application (type 56) [24]. In this software the information about the buildings are implemented with TRNSYS3d, a Google SketchUP plugin [26]. In particular, geometric shape, exposure, and part of the layout of the rooms of the school buildings were used to model the thermal behavior of the building in TRNSYS3d. A simplification of the building geometry is performed in order to assess a reliable thermal model of the building, and to avoid an excessively long computational time. In the building model are also implemented the thermo-physical characteristics of all the architectural elements of the considered buildings (windows, internal and external walls, Table 3) The simulated buildings are divided into thermal zones identified by the exposure of the zone, intended use, thermal loads and ventilation rate. In particular, the schools "II Circolo" and "Leonardo da Vinci" are modeled with three thermal zones. In addition, two other thermal zones are identified for the gym attached to the "Leonardo da Vinci" school (Table 4 and Table 5).

For the model of each thermal zone are assumed:

1. spatial uniformity of the air temperature;

2. unique value of the temperature set-point;

3. the same type of space conditioning installation.

In addition, for each zone the scheduling regarding the occupancy, based on data collected in the field, are used. In order to validate the proposed model a study about the buildings energy consumption was performed, in particular an energetic audit allowed to obtain an estimation of the buildings consumption in the steady state conditions. The collected data was used to compare the simulation results and to validate the building thermal model (omitted here for sake of brevity). 
Table 3. Input parameters of the geometric and material building models

\begin{tabular}{|c|c|c|}
\hline & II Circle & L. da Vinci \\
\hline Heated Floor Area & $487.0 \mathrm{~m}^{2}$ & $795.6 \mathrm{~m}^{2}$ \\
\hline Heated Volume & $4603.6 \mathrm{~m}^{3}$ & $7945.6 \mathrm{~m}^{3}$ \\
\hline $\begin{array}{l}\text { Ext. Wall Thermal } \\
\text { Transmittance }\end{array}$ & $0.262 \mathrm{~W} /\left(\mathrm{m}^{2} \mathrm{~K}\right)$ & $0.262 \mathrm{~W} /\left(\mathrm{m}^{2} \mathrm{~K}\right)$ \\
\hline $\begin{array}{l}\text { Roof Thermal } \\
\text { Transmittance }\end{array}$ & $0.458 \mathrm{~W} /\left(\mathrm{m}^{2} \mathrm{~K}\right)$ & $0.458 \mathrm{~W} /\left(\mathrm{m}^{2} \mathrm{~K}\right)$ \\
\hline $\begin{array}{l}\text { Ground-Slab Thermal } \\
\text { Transmittance }\end{array}$ & $0.995 \mathrm{~W} /\left(\mathrm{m}^{2} \mathrm{~K}\right)$ & $0.995 \mathrm{~W} /\left(\mathrm{m}^{2} \mathrm{~K}\right)$ \\
\hline $\begin{array}{l}\text { Glazing Thermal } \\
\text { Transmittance }\end{array}$ & $1.27 \mathrm{~W} /\left(\mathrm{m}^{2} \mathrm{~K}\right)$ & $1.27 \mathrm{~W} /\left(\mathrm{m}^{2} \mathrm{~K}\right)$ \\
\hline $\begin{array}{l}\text { Frame Thermal } \\
\text { Transmittance }\end{array}$ & $2.26 \mathrm{~W} /\left(\mathrm{m}^{2} \mathrm{~K}\right)$ & $2.26 \mathrm{~W} /\left(\mathrm{m}^{2} \mathrm{~K}\right)$ \\
\hline Solar Factor Glazing & 0.5 & 0.5 \\
\hline
\end{tabular}

Table 4. Thermal Load per thermal zone

\begin{tabular}{ccc}
\hline & \multicolumn{2}{c}{ Thermal Load } \\
\cline { 2 - 3 } & People & $\begin{array}{c}\text { Light gain } \\
\left(\mathrm{W} / \mathrm{m}^{2}\right)\end{array}$ \\
II Circle & & \\
$\bullet \quad$ Zone 1 & 37 & 10 \\
$\bullet \quad$ Zone 2 & 70 & 10 \\
$\bullet \quad$ Zone 3 & 308 & 10 \\
Leonardo da Vinci & & \\
$\bullet \quad$ Zone 1 & 37 & 10 \\
$\bullet \quad$ Zone 2 & 70 & 10 \\
$\bullet \quad$ Zone 3 & 308 & 10 \\
Gym Building & & \\
$\bullet \quad$ Zone 1 & 47 & 5 \\
$\bullet \quad$ Zone 2 & 39 & 5 \\
\hline
\end{tabular}

Table 5. Use and Rate Ventilation per thermal zone

\begin{tabular}{cccc}
\hline II Circle & Use & $\begin{array}{c}\text { Ventilation rate } \\
\text { (vol/h) }\end{array}$ \\
\hline$\bullet \quad$ Zone 1 & $8: 00-13: 00$ & 0.8 \\
$\bullet \quad$ Zone 2 & $8: 00-13: 00$ & 0.8 \\
$\bullet \quad$ Zone 3 & $8: 00-13: 00$ & 0.8 \\
Leonardo da Vinci & & \\
$\bullet \quad$ Zone 1 & $8: 00-13: 00$ & 0.8 \\
$\bullet \quad$ Zone 2 & $8: 00-13: 00$ & 0.8 \\
$\bullet \quad$ Zone 3 & $8: 00-13: 00$ & 0.8 \\
Gym Building & & \\
$\bullet \quad$ Zone 1 & $8: 00-13: 00$ & 0.8 \\
$\bullet \quad$ Zone 2 & $8: 00-13: 00$ & 0.8 \\
\hline
\end{tabular}

\subsection{Reversible heat pump}

A reversible heat pump, HP, was used for district heating purposes. In particular, a single-stage reversible water-towater heat pump was considered. In the system model, the heat pump was simulated by implementing the type 668 of TRNSYS library [25] based on user-supplied data files. In particular, the user-supplied data consists of heating capacity and power consumption for the different operating conditions obtained by manufacturer catalog data. The performance data files were generated taking into account the load value, the source temperatures and liquid mass flow rates for both evaporator and condensator sides of the heat pump. Thus, manufacturer data were used by the authors in order to validate the model of the component. In particular, an AERMEC $^{\circledR}$ WSA [27] reversible heat pump type was selected.

\subsection{Pipe}

The district heating system network and the hydronic system of each school building is realized with a piping system. In particular, the piping is adopted in order to transport the hot fluid to the users of the district heating network, while for the building hydronic system the pipes are used to distribute the hot fluid to the fan coil system. For this purposes, the TRNSYS built-in Type 31 pipe was selected. In order to perform the thermal behavior of the fluid flow inside the pipe or duct, the component is modelled using variable size segments of fluid flow. In particular, the pipe fluid dynamic is modelled with a plug-flow regime where no mixing and conduction effects between adjacent segments are considered.

The piping system is implemented in order to take into account the dynamic behavior of the DH network and of the building hydronic system. In a DH system there is a time delay between the heating production and the thermal energy supply to the network users due to flowing fluid velocity. In particular, the heated fluid produced in the heating plant reaches the users after a time interval defined by the ratio of piping length and fluid velocity. This effect is major in the DH system with respect to the hydronic system where the piping length is significantly lower. Moreover, the implementation of the pipe model listed above allows to calculate the piping system thermal losses for both $\mathrm{DH}$ and hydronic systems. The heat loss exchange coefficients for the piping systems were accurately evaluated taking into account the different type of pipe installation (buried or building integrated).

\section{RESULTS}

The performance of both systems were analyzed trough daily, monthly and annual simulations. A time step of 0.1 hour was selected in order to promote the convergence of simulations.

\subsection{Daily results}

One typical day, February $14^{\text {th }}$, for winter season was selected as example, of dynamic operation of the system. In Figure 4 are shown the daily trends of electrical and thermal energies and the trend of Coefficient of Performance, COP, for Central Thermal Plant DH configuration.

During the first hours of the day, when the buildings heating system is turned on, the electric and thermal energy demand (EE,HP and TE,REQ) is very high. This occurs because the buildings air temperature decreased during the night hours. After 8:00 a.m., the demand it rapidly decreases due to internal gains (people and devices) and solar radiation.

It is important to note that, the electric consumption of the heat pump is significant due to the network thermal losses. It can be observed that the network thermal losses remain even when the buildings thermal demand is reset due to the difference between the network hot water and ground temperature. Moreover, the COP of the heat pump is almost constant during operating hours.

In Figure $\mathbf{5}$ daily result for Substation DH configuration are presented. In this configuration, the network water temperature is approximately $27^{\circ} \mathrm{C}$ because the heat pumps are located in the substations of schools. As consequence, the network thermal losses are significantly lower compared to 
the first configuration due to a smaller temperature difference between water and ground $\left(55^{\circ} \mathrm{C} \div 15^{\circ} \mathrm{C}\right.$ versus $\left.27^{\circ} \mathrm{C} \div 15^{\circ} \mathrm{C}\right)$. The electric energy demand (EE, HP1, EEHP2) of both heat pumps is lower with respect to the single heat pump installed in the first configuration. This occurs because the heat pumps do not supply thermal energy for the heating of district network water.

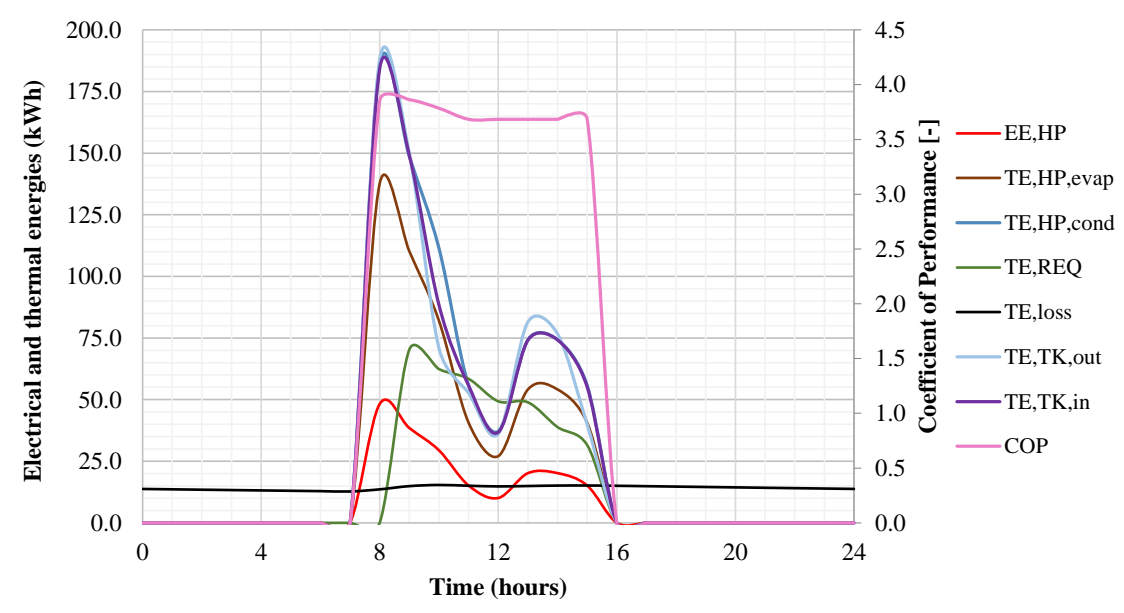

Figure 4. Daily results for Central Thermal Plant DH configuration

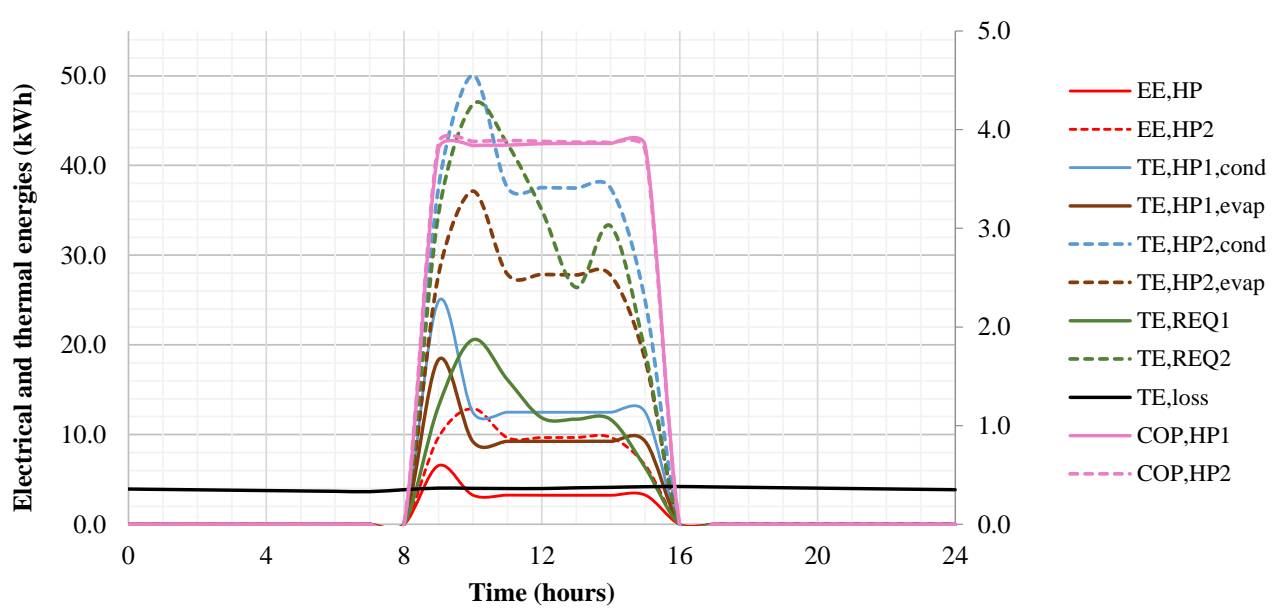

Figure 5. Daily results for Substation DH configuration

\subsection{Monthly results}

Monthly values of thermal and electric energies are shown in Figure 6 and Figure 7 for thermal central and substation DH configuration, respectively.

In the first case, the thermal energy demand of the buildings, TE, REQ, is very high in December, January and February in according to the relatively low external air temperature.

The thermal energy supplied by the tank, TE,TK,OUT, is the energy sent to district network and it is obviously highest than the sum of the grid thermal losses, TE,loss, and the energy request of buildings TE,REQ. It must be noted that the thermal energy losses are higher than the buildings energy demand. In particular, the first one is $74 \%$ and $28 \%$ higher with respect to the second one in November and February, respectively. Only in January the energy demand is $27 \%$ greater than the energy losses due to the relatively high building thermal demand in such month.

As discussed before, the district hot water returns to the tank within the district network closed loop; the return water temperature is decreased respect to the input one temperature due to grid thermal losses and due to the heat exchanged in the substation, needed to supply the heat pump and to heat the inertial tank. In fact, the thermal energy supplied by the condenser, TE,HP,cond, is approximately equal to the input thermal energy of the tank (TE,TK,in). The negligible difference between TE,HP, cond and TE,TK,in is due to the thermal loss of the loop between the heat pump and the tank. Finally, in Figure 6 is reported the electric energy consumption of the heat pump. The relatively low electrical energy consumption is due to the high efficiency unit in terms of COP value (3.80). The monthly COP value is approximately constant because the geothermal source temperature and the variation of the condenser inlet temperature are almost constant during the heat pump operation.

In Figure 6 are reported the results of substation DH configuration simulations. The thermal energy and electric energy values reported take in account both heat pumps and inertial tanks located in the substations. In the substation DH configuration, the EE,HP and TE,HP are the electric energy consumption and the thermal energy production of both substations heat pumps respectively. In this case, the difference between the TE,HP,cond and TE,REQ is reduced with respect to the first configuration because the only thermal losses that affect this difference are relative to the shorter "heat pump-tank" and "tank-fan-coil" loops. The TE 
loss, reported in Figure 7, denotes the thermal energy losses in the network loop, this value is $65 \%$ lower per every month with respect to the central thermal configuration due to a smaller gap between the ground and water loop temperature.

Finally, the TE,TK,in and TE,TK, out are reported; the difference represents the thermal losses of the tanks. The thermal losses are higher with respect to the central configuration because the storage tanks volume in the substation configuration are lower and, as a consequence, the losses are higher at the same temperature conditions (central and substation configuration)

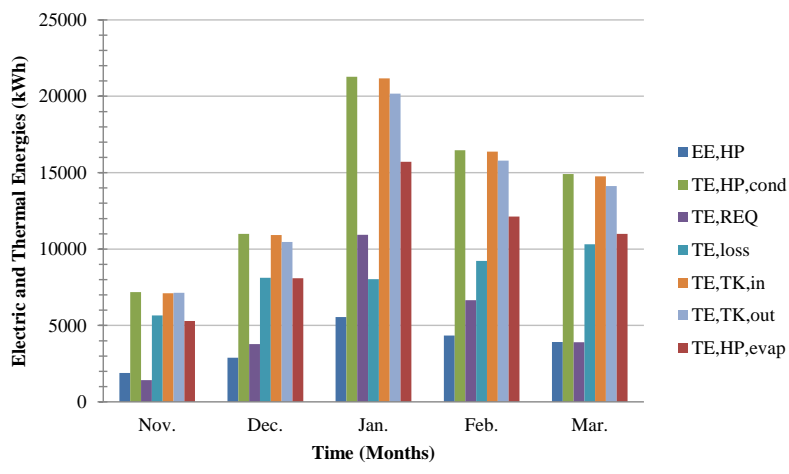

Figure 6. Monthly results for Central Thermal Plant DH configuration

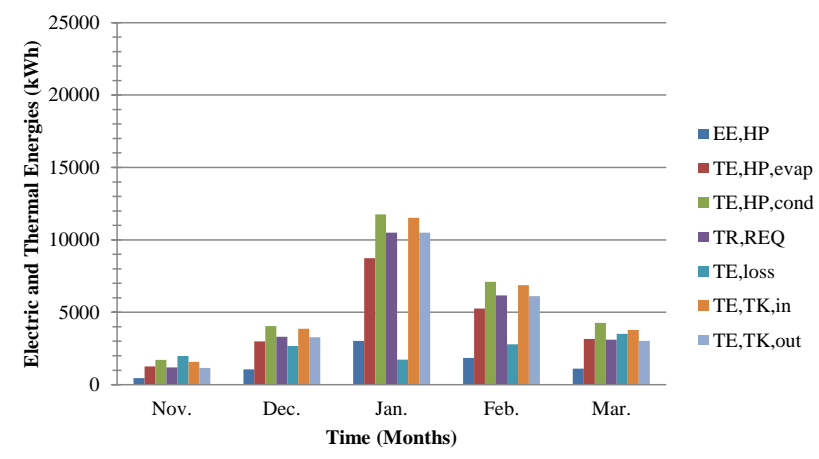

Figure 7. Monthly results for Substation DH configuration

\subsection{Yearly results}

Table 6. Thermal Load per thermal zone

\begin{tabular}{lllll}
\hline Parameter & $\begin{array}{l}\text { Central } \\
\text { configuration }\end{array}$ & \multicolumn{2}{l}{$\begin{array}{l}\text { Substation } \\
\text { configuration } \\
\text { II Circolo }\end{array}$} & L. da Vinci \\
\hline EE,aux & $1.68 \mathrm{E}+04$ & $1.01 \mathrm{E}+04$ & & $\mathrm{kWh} /$ year \\
\hline EE,HP & $2.04 \mathrm{E}+04$ & $2.38 \mathrm{E}+03$ & $5.45 \mathrm{E}+03$ & $\mathrm{kWh} /$ year \\
\hline TE,HP,cond & $7.78 \mathrm{E}+04$ & $9.24 \mathrm{E}+03$ & $2.10 \mathrm{E}+04$ & $\mathrm{kWh} /$ year \\
\hline TE,HP,eva & $5.74 \mathrm{E}+04$ & $6.86 \mathrm{E}+03$ & $1.55 \mathrm{E}+04$ & $\mathrm{kWh} /$ year \\
\hline TE,TK,in & $7.72 \mathrm{E}+04$ & $8.57 \mathrm{E}+03$ & $2.05 \mathrm{E}+04$ & $\mathrm{kWh} /$ year \\
\hline TE,TK,out & $7.35 \mathrm{E}+04$ & $6.81 \mathrm{E}+03$ & $1.79 \mathrm{E}+04$ & $\mathrm{kWh} /$ year \\
\hline TE,loss & $4.66 \mathrm{E}+04$ & $1.49 \mathrm{E}+04$ & & $\mathrm{kWh} /$ year \\
\hline TE,REQ & $2.73 \mathrm{E}+04$ & $6.81 \mathrm{E}+03$ & $1.81 \mathrm{E}+04$ & $\mathrm{kWh} /$ year \\
\hline SCOP & $3.81 \mathrm{E}+00$ & $3.88 \mathrm{E}+00$ & $3.85 \mathrm{E}+00$ & - \\
\hline
\end{tabular}

The results on a yearly basis are presented in this section for both configurations.

Considering the same buildings energy demand, the auxiliary equipment (pumps and fans) and heat pumps electric energy consumptions, EE,aux and EE,HP, in the substation configuration are $40 \%$ and $62 \%$ lower with respect to the central thermal plant configuration, respectively.

The thermal energy production by the heat pump and the thermal energy supplied from the tank in the central $\mathrm{DH}$ configuration is $61 \%$ and $66 \%$ higher than the second one.

The value of seasonal performance coefficient of heat pumps remains almost the same for both configurations.

\section{CONCLUSION}

The energetic feasibility of the realization of a fourth generation district heating network for the city of Mondragone in Southern Italy is analyzed. In particular, the study focuses on the first stage of operation the district heating, where only two school buildings are connected to the network

The performed analysis provides detailed data about the energetic performance of the geothermal district heating system. Moreover, two district heating system configurations are considered, centralized and decentralized (substation) heat pump installation.

The analysis carried out shows that:

- the adoption of a fourth generation district heating system must be coupled with an improvement of the energetic performance of the building (building and facade requalification), due to the low district supply temperature and to the adoption of low temperature heating terminals;

- the district heating network with a central heat pump configuration has a $62 \%$ higher electric energy consumption with respect to the one with two heat pumps installed in each building substation. This is due to the thermal energy supplied to the network in order to ensure its operating temperature $\left(55^{\circ} \mathrm{C}\right)$

\section{ACKNOWLEDGMENT}

The authors would like to acknowledge the financial support of the VIGOR Project, CUP. VIGOR is part of the activities of the Interregional Programme "Renewable Energies and Energy Savings FESR 2007-2013 - Axes I Activity line 1.4 "Experimental Actions in Geothermal Energy".

\section{REFERENCES}

[1] Lorenzini E. and Mirandola A. "Energy, Environment and Climate: From the past to the future," International Journal of Heat and Technology, vol. 34, no. 2, June 2016, pp. 159-164 DOI: 10.18280/ijht.340201.

[2] European Commission (2010, March). Communication from the Commission Europe 2020 a strategy for smart, sustainable and inclusive growth. [Online]. Available:

http://eurlex.europa.eu/LexUriServ/LexUriServ.do?uri $=$ COM:2010:2020:FIN:EN:PDF 
[3] Leyla Ozgener, Arif Hepbasli and Ibrahim Dincer, "Effect of reference state on the performance of energy and exergy evaluation of geothermal district heating systems: Balcova example," Building and Environment, vol. 41, pp 699-709, 2006. DOI: 10.1016/j.buildenv.2005.03.007.

[4] Directive 2009/28/Ec of the European Parliament and of the Council, April 23, 2009.

[5] R. Bertani, "Geothermal power generation in the world 2005-2010," Geothermics, vol. 41, pp.1-29, Jan. 2012. DOI: $10.1016 /$ j.geothermics.2011.10.001.

[6] R. Bertani, "Geothermal power generation in the world 2010-2014 update report," Geothermics, vol. 60, pp. $31-43$, Mar.2016.

DOI: 10.1016/j.geothermics.2015.11.003.

[7] Calise F., Capuozzo C., Carotenuto A. and Vanoli, L. "Thermoeconomic analysis and off-design performance of an organic Rankine cycle powered by medium-temperature heat sources," Solar Energy Volume 103, May 2014, pp. 595-609. DOI: 10.1016/j.solener.2013.09.031.

[8] Carotenuto A., Di Fraia S., Massarotti N., Mauro A. and Paderni G. "Finite element modeling of vertical energy piles," 3rd International Conference on Computational Methods for Thermal Problems, ThermaComp 2014, pp. 204-207. ISBN: 978887431727-1.

[9] R. Di Pippo, Geothermal Power Plants- Principles, Applications, case Studies and Environmental Impact, Second edition. Elsevier Ltd.

[10] Ines B., Ines A. and Abdallah M., "Experimental determination of thermal conductivity and diffusivity of new building insulating materials," International Journal of Heat and Technology, vol. 34, no. 2, June 2016, pp. 325-331 DOI: 10.18280/ijht.340224.

[11] J. Ivner and S. B. Viklund. "Effect of the use of industrial excess heat in district heating on greenhouse gas emissions: A systems perspective," Resources, Conservation and Recycling, vol. 100, pp. 81-87, Jul. 2015. DOI: 10.1016/j.resconrec.2015.04.010 09213449/C 2015 Elsevier B.V. All rights reserve.

[12] A.N. Ajah, A. C. Patil, P. M. Herder and J. Grievink. "Integrated conceptual design of a robust and reliable waste-heat district heating system," Applied Thermal Giustini F., Gola G., Iavarone M., Inversi B., Iorio M., Langella G., Livani M., Losanno S., Manzella A., Maraio S., Massarotti N., Mauro A., Meo S., Mercadante A., Minissale A., Montanari D., Montegrossi G., Mussi M., Pandolfi L., Pelosi N., Petracchini L., Petruccione E., Pischiutta M., Polemio M., Punzo M., Quattrocchi F., Recanati R., Rizzo E., Romano C., Romi A., Rovelli A., Sarnacchiaro G., Scotto di Vettimo P., Scrocca D., Tamburrino S., Tarallo D., Tedesco D., Testa B., Tiano P., Vanoli L., Varriale F. (2015). VIGOR: Sviluppo geotermico nella regione Campania - Studi di Fattibilità a Mondragone e Guardia Lombardi. Progetto VIGOR - Valutazione del Potenziale Geotermico delle Regioni della Convergenza, POI Energie Rinnovabili e Risparmio Energetico 2007-2013, CNR-IGG, ISBN: 9788879580151 .

[20] Available: http://www.comune.mondragone.ce.it/

[21] UNI 10349:1994 EC "Riscaldamento e raffrescamento degli edifici- Dati climatici," Dic. 1997

[22] Corniello, A., Cardellicchio, N., Cavuoto, G., Cuoco, E, Ducci, D., Minissale A., Mussi, M, Petruccione, E.,
Engineering, vol.27, n.7, pp. 1158-1164, May 2007. DOI: 10.1016/j.applthermaleng.2006.02.039.

[13] E. Biele , D. Di Santo , D. Ovens and G. Tomassetti, "Survey on knowledge and dissemination of district heating in the common areas and in and $\mathrm{F}$ and analysis of the three data networks," ENEA, September, 2014.

[14] A. Colmenar-Santos, E. Rosales-Asensio, D. BorgeDiez and J. Balnes-Peirò, "District heating and cogeneration in the EU-28: Current situation potential and proposed energy strategy for its generalisation," Renewable and Sustainable Energy Reviews, vol. 62, pp. 621-639, Sep.2016. DOI: 10.1016/j.rser.2016.05.004

[15] N. Aste, M. Buzzetti and P. Caputo. "District heating in Lombardy region (Italy): Effect of supporting mechanisms," Sustainable Cities and Society, vol. 14, pp. 43-55, Feb. 2015. DOI: 10.1016/j.scs.2014.07.006.

[16] C. Delmastro, G. Mutani, L. Schranz, "Advantages of coupling a woody biomass cogeneration plant with a district heating network for a sustainable built environment: a case study in Luserna San Giovanni (Torino, Italy)," $6^{\text {th }}$ International Building Physics Conference, IBPC.2015.Availabe: http://www.sciencedirect.com/science/article/pii/S1876 610215018342.

[17] M. Cordoli, S. Vincenzi and G. A. De Leo, "Effect of heat recovery for district heating on waste incineration health impact: a simulation study in Northern Italy," Science of the Totale Environment, vol. 444, pp. 369380, Feb. 2013. DOI: 10.1016/j.scitotenv.2012.11.079.

[18] L. Ozgener, A. Hepbasil and I. Dincer, "Energy and exergy analysis of geothermal district heating systems: An application," Building and Environment, vol. 40, pp. 1309-1322, Oct. 2005. DOI: 10.1016/i.buildenv.2004.11.001.

[19] Amoresano A., Angelino A., Anselmi M., Bianchi B., Botteghi S., Brandano M., Brilli M., Bruno P.P., Caielli G., Caputi A., Cardellicchio N., Carotenuto A., Cavuoto G., Chiarabba C., Chiesa S., Ciccolella M., Corniello A., Cuoco E., de Fenzo B., De Franco R., De Lisa G., De Luca G., del Vecchio U., Di Bella G., di Fiore V., di Gregorio C., Di Leo M., Donato A., D’Oriano A., Ducci D., Fedi M., Ferrante L., Florio G., Gargiulo V., Gimelli A., Giocoli A., Pelosi, N., Rizzo, E., Polemico, M., Tamburino, S., Tedesco, D., Tiano, P., and Iorio, M. "Hydrogeological characterization of a geothermal system: The case of the thermo-mineral area of Mondragone (Campania, Italy)," Int. J.Environ.Res., vol. 9, no. 2, pp. 523-534, 2015. ISSN:1735-6865

[23] D.P.R. 26 agosto 1993, no. 412. "Regolamento recante norme per la progettazione, l'installazione, l'esercizio e la manutenzione degli impianti termici degli edifici ai fini del contenimento dei consumo di energia, in attuazione dell'art.4, comma 4, della L.9 gennaio 1991, n.10.

[24] Klein SA, et al., Solar Energy Laboratory, TRNSYS. A transient system simulation program. University of Wisconsin, Madison. 2006 Available: http://sel.me.wisc.edu/trnsys/features/features.html

[25] “TRNSYS 16 - a TRaNsient System Simulation program-Mathematical reference," Vol.5.

[26] SketchUP ${ }^{\circledR} \quad$ Software. 2016 Available: https://www.sketchup.com/it 
TE,TK,OUT http://global.aermec.com/it/

NOMENCLATURE

COP

$\mathrm{D}$

DHN

DHW

EE,aux

EE,HP

ET,HP,cond

TE,loss

TE,REQ

TE,TK,in
Coefficient Of Performance

Diverters

Dictrict Heating Network

District Hot Water

Auxiliary electric energy consumption

Electric Energy Consumption of HP

HP Condenser Thermal Energy

Network Thermal Energy Losses

Building Thermal Energy Demand

Input Thermal Energy of the Tank
$\mathrm{FC}$

HEWE

HGHE

HGF

HP

HPHTF

HRWE

HW

$\mathrm{M}$

$\mathrm{P}$

SHE

$\mathrm{S} / \mathrm{V}$

TK
Out Thermal Energy of the Tank Fan Coil

Geothermal Extraction Well Geothermal Heat Exchanger Hot Geothermal Fluid Water to Water Heat Pump Heat Pump Heat Transfer Fluid Geothermal Reinjection Well Buildings Hot Water Flow Mixers

Pump

Substation Heat Exchanger Surface area to Volume ratio Thermal Regulation Tanks 